\title{
Integrated Watershed Management and Sedimentation
}

\author{
Molla Mekonnen Alemu \\ United Nations Development Programme, Freetown, Sierra Leone \\ Email: mollamekonnen@gmail.com
}

Received 15 January 2016; accepted 5 March 2016; published 9 March 2016

Copyright (C 2016 by author and Scientific Research Publishing Inc.

This work is licensed under the Creative Commons Attribution International License (CC BY). http://creativecommons.org/licenses/by/4.0/

(c) (i) Open Access

\section{Abstract}

Environmental development and protection measures such as feasibility studies, land-use planning and soil and water conservation are some of the issues that need to be considered in watersheds management. Apparently, integrated watershed management is emerging as an approach for the sustained development and management of natural resources. The integral enactment of different environmental frameworks, strategies and policies could positively impact watershedbased developmental approaches. Sediment which is brought through water erosion can hamper the proper functioning of waterways as well as the quality of water in dams. Knowhow on soil erosion and the sedimentation process is among the requisites that need to be considered for the control of sedimentation. Other elements like climate, edaphic factors, land management, topography, and land cover, etc. will also determine the sedimentation process. Integrated Watershed Management approach is a worthy approach to manage the ecological, social and economic watershed development challenges in countries like Ethiopia. Thus, this article is intended to assess watershed characteristics that will help to explore the possibilities of reducing sedimentation and its related effects.

\section{Keywords}

Integrated, Watershed, Soil, Water Conservation

\section{Introduction}

Different names has been adopted for the term watershed like Watershed (USA) and drainage basin (USA), catchments (British), and in some others drainage area. These all would agree that watershed/drainage basin/is an area drained by a stream of/or a system of connecting streams in such a way that all flow originating in that area 
is discharged through a single outlet. Chow cited by Nigussie [1] stated that the watershed was a divide separating one drainage basin from another and others have defined it as a geographical unit in which the hydrological cycle is complete and its components can be analyzed. This geographical unit is one of the possible intervention points for sustainable land management where monitoring and impact assessment for sustainable land management could be addressed.

In Ethiopia, there exists an increasing attention toward the improvement of water resources development, integrated watersheds management, and increasing production and productivity of land resources. Soils erosion can cause losses of biodiversity, decrease the productivity of land, sedimentation and frequent occurrence of natural disasters such as floods. Sediments transported from farmlands can bring toxic substances into water reservoirs. Sediments can also block waterways and cause flood hazards and other associated health problems.

The water carrying capacity of reservoirs can also be lowered dramatically as a result of sedimentation which will in turn affect the objective and productivity of different investments on reservoirs. Therefore, having a proper prediction of sediment delivery is an important factor in managing the impacts of sediments for the efficient utilization of land resources and environmental development efforts. Sedimentation involves soil erosion, transportation and deposition of sediment processes. Different factors like climate, edaphic factors, land management, topography, and land cover, human activities etc. are also determinants of sediment delivery [2].

Coarse textured sediments and sediment particles from rill and sheet erosion have a greater likelihood of being deposited as compared to the fine sediment particles. Therefore, this implies that the transport of sediment with coarse texture or from sheet and rill erosion is comparatively lesser than the fine sediment or sediment coming from channel erosion. The concentration of channel within the watershed has a great impact on the amount of sediment delivery. For instance, a small sized watershed which has a greater number of channels will have greater sediment delivery ratio as compared to a large sized watershed that has a small amount of channels in it. In terms of topography too, a watershed with steeply slopes in it will have a greater amount of sediment transport proportion than a watershed with level and wide topographic orientation. Therefore, in order to overcome these and other similar challenges and impacts of sedimentation, the integrated watershed management approach can play a paramount role as it helps to address the different factors in an integral way.

\section{Objective}

The objective of this paper is to review and explore watershed and sedimentation characteristics in the context of integrated watershed management approach that will help the promotion of sustained agricultural production.

\section{Methodology}

For the compilation of this paper, different literatures on integrated watershed management and sedimentation were reviewed from books, journals and proceedings. Practical field level observations were also captured in the synthesis of the paper. The paper also identified the major factors that have been observed in the extension of integrated watershed management approach.

\section{Results and Discussion}

\subsection{Definition and Scope of Integrated Watershed Management}

For the term watershed, different names has been adopted which includes watershed (USA), drainage basin (USA), catchments (British), and in some other places drainage area. However, these all would agree that watershed/drainage basin/is an area drained by a stream of /or a system of connecting streams in such a way that all flow originating in that area is discharged through a single outlet. According to Chow cited by Nigussie [1] the watershed is a divide separating one drainage basin from another. Others have defined it as a geographical unit in which the hydrological cycle is complete and its components can be analyzed.

Nigusse [1] mentioned that according to their size watersheds may be classified into: Major watersheds, Medium watersheds, and Sub-watersheds.

The major watersheds are tributaries to river basins and they may cover an area of land which range from 20,000 to 500,000 hectares of land. In this category, there can be a variety of ecosystems and agro-ecological zones.

The medium watersheds are areas of land which exhibits a similar ecological setting with in it and the size 
could be 5000 - 20,000 hectares.

The sub-watersheds include sizes of $<5000$ hectares of land. This category of watersheds can easily be used for a detailed development plan, which could include a very detailed work plan whereby soil and water conservation measures, afforestation programmes, forage and pasture management, etc. plans can be implemented.

\subsection{Erosion and the Sedimentation Processes}

Topography, climate, land use, land cover, edaphic factors, etc. are some of the factors that influence the production and transportation of sediment within a watershed area. Irregular and spatially capricious progressions of erosion will determine the flow of sediment and water.

The prime agents of water erosion are the falling rain drops and the running water. When rain drops fall on the soil, it will break up the soil aggregates and splash the finer particles outwards, exposing them to be moved away by the running water very easily. On a steeply land, more than half of the splashed particles and water moves downhill and many of the small particles seal up pores in the soil's B horizon.

As the soil becomes progressively shallower, it becomes more easily saturated and both soil detachment and transport are easier and greater runoff. Increased runoff has increased strength to detach and transport soil particles while the cohesion of the soil itself is being reduced by erosion taking away the finer particles.

GLC [3] mentioned as the erosion process could include-detachment of the soil particles as a result of the rainfall; sheet erosion and transport of particles; gully erosion; degradation of waterways and bank; soil erosion caused by slope of the land and wind erosion.

Sediment yield is the total volume of sediment that passes through a definite waterway whereby the process of sedimentation is governed by a set of geomorphic processes. Sediment yield is usually expressed in units of cubic meters/kilometer square/annum or metric tons per annum. In order to know the magnitude of erosion, it is also however imperative to estimate the amount of sediment yield from individual showers of rain.

The movement of sediment is impacted by the general situation of the wind and water. Deposition of sediments can occur in different places where the eroding agent energy becomes low.

\subsection{Ecological and Economic Impacts of Erosion}

Erosion can drastically reduce the productivity of land which will in turn impact the agricultural production potentials. Sedimentation can also cause for the loss of plants that are at seedling stage. Apart from this, sedimentation can fill reservoirs, drainage systems, and other water bodies like rivers, streams and lakes.

Erosion can minimize economic potentials since it reduces the income from agricultural yields as a result of the low productivity of farm lands. Erosion can also damage the quality of life through decreased economic returns at household and country level incomes, weak quality of water and additional costs for sediment removal and maintenance of drainage systems,

Erosion is also among the primary causes for the degradation of aquatic habitats as a result of sedimentation and silting up of water bodies which will affect the very existence of aquatic biodiversity [4].

Suspended sediments resulted from erosion will hamper the transmission of light in water bodies which will affect the entire photosynthesis process as a result of shortage of sunlight. This can result in the reduction of the growth of algae and other aquatic plant and animal species that can harmfully disturb the entire aquatic ecosystem. In addition to this, it can affect the touristic values of the ecosystem and thereof negative impact on livelihood, economic and ecological returns. Erosion can also affect the water quality since it transports fertilizers, pesticides, etc. in to the public water systems that use them as a source of drinking water [5].

\subsection{Integrated Watershed Management as an Option to Combat Erosion and Sedimentation}

Integrated Watershed Management is a method of handling human activities and natural resources on a watershed basis. The method allows the conservation and development of water and other land resources in an integrated way in a specific delineated area of land (Figure 1).

A number integrated watershed management principles can be adopted based on the specific settings of watershed, but the general ones could include the following.

Agronomic management methods integrated with sound soil and water conservation and development 


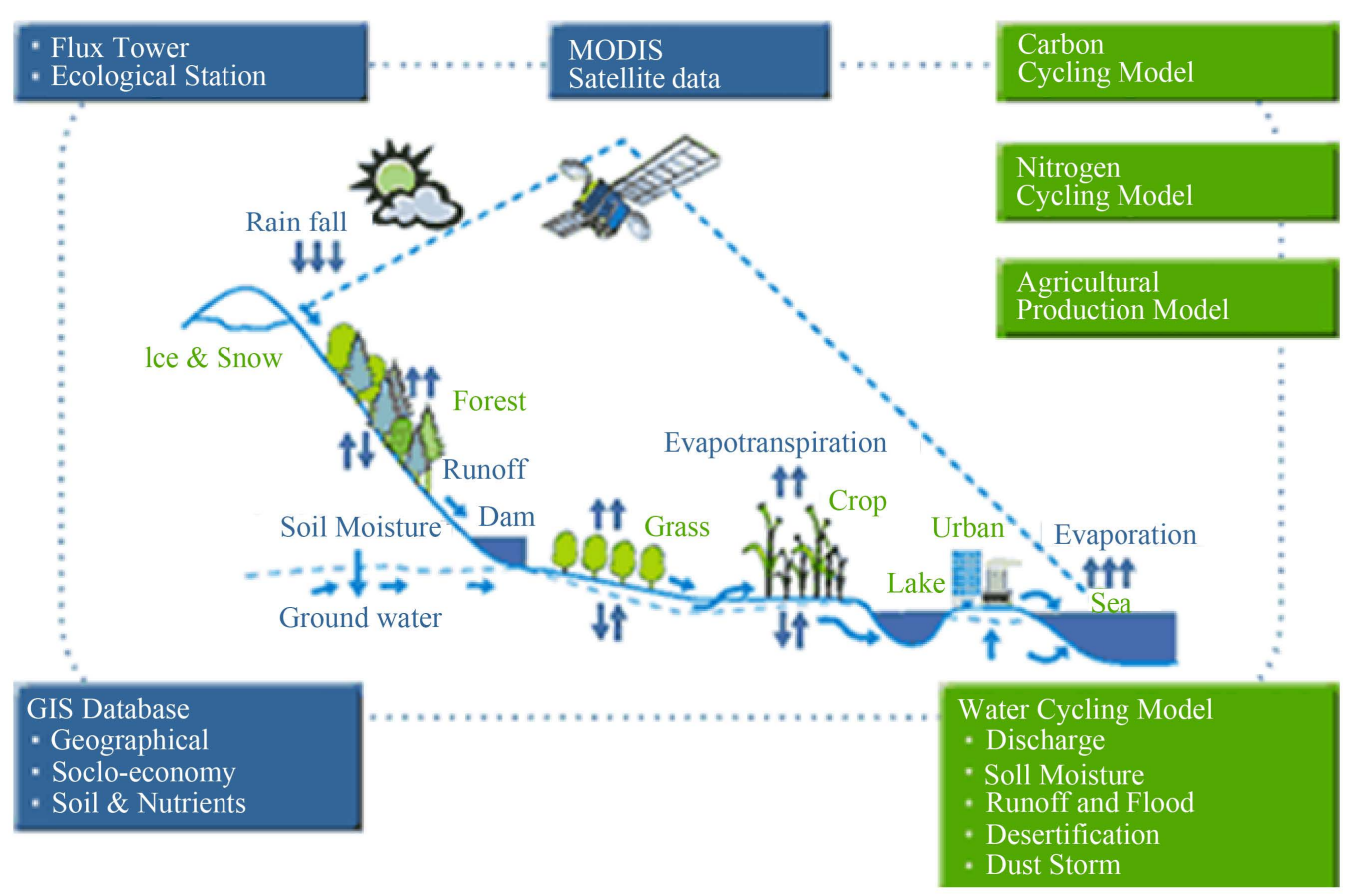

Figure 1. Structure of the integrated watershed management model [6].

techniques can reduce the impact of the erosion and sedimentation processes. This could also help to maximize the infiltration potentials of the soil. The agronomic activities can include crop and vegetation management, crop rotation, shifting cultivation, grazing land management, etc. [7].

In terms of cost, the agronomic measures of soil and water management are less costly and demands less labour in terms of reducing raindrop impact on soil detachment process, increasing infiltration capacity, reducing runoff volume, increasing productivity of the land and decreasing wind and water velocities in an integrated way. This method, however, requires time to get well established [8].

Mechanical methods of water and soil conservation are not productive by their own as the physical structures can't stop the detachment and loosening of soil particles. They are, however, effective when used in an integrated way with the agronomic practices where they will be effective in controlling excessive runoff and wind. The establishment cost of mechanical methods is also labour and cost demanding and can be associated with negative impacts like rats, narrowing farmable field size, etc.

\section{Concluding Remarks}

Watershed soil erosion and reservoir sedimentation are some of the major environmental problems that reduce the productivity of land resources in Ethiopia. The Integrated Watershed Management approach, as evolved in recent years, should be employed to harmonize the comprehensive objectives of increasing agricultural productivity and production. Therefore, the proper designing of integrated watershed management and conservation strategies is a crucial element to reduce the current rate of environmental degradation and boost up agricultural production in the country.

\section{References}

[1] Nigussie, H. (2008) Watershed Management Lecture Note for Postgraduate Students for the Course Integrated Watershed Management. Mekelle University, Ethiopia.

[2] Ouyang, D. and Bartholic, J. (1997) Predicting Sediment Delivery in Saginaw Bay Watershed. Institute of Water Research, Michigan State University, East Lansing.

[3] GLC (Great Lakes Commission) (1997) Application of Methods and Models for Prediction of Land Surface Erosion and Yield, TD 36, March 1995, Hydrologic Engineering Center Compendium of Tools for Watershed Assessment and TMDL Development, EPA841-B97-006. 
[4] William, A. (2007) Erosion and Sedimentation. The Gale Group Inc., New York

[5] Tarbuck, E.J. and Lutgens, F.K. (1998) The Earth: An Introduction to Physical Geology. 6th Edition, Prentice Hall, New York.

[6] APEIS (Asia-Pacific Environmental Innovation Strategy) (2003) Integrated Environmental Monitoring, Technical Summary. https://www.env.go.jp/en/earth/ecoasia/APEIS/iem/index.html

[7] Verheye, W.H. (2010) Soils, Plant Growth and Crop Production, Volume I. Encyclopedia of Life Support Systems (EOLSS).

[8] REMA (2010) Practical Tools on Soil and Water Conservation Measures, Republic of Rwanda, Kigali. Rwanda Environment Management Authority, Kigali. 